\title{
Enhanced Fischer-Tropsch Synthesis Rates by the Combined Presence of Aqueous and Organic Media in Biphasic Systems
}

\author{
Supporting Information
}

Felipe Anaya and Daniel E. Resasco*

The University of Oklahoma, Center for Interfacial Reaction Engineering

School of Chemical, Biological, and Materials Engineering,

100 East Boyd St., Norman, OK 73019, USA

*Corresponding author ( resasco@ou.edu ) 


\section{Ethylene hydrogenation measurements to estimate metal dispersion}

First, ethylene hydrogenation rates at 5\% conversion were measured in a fully characterized $\mathrm{Ru} / \mathrm{TiO}_{2}$ catalyst (Table S1). $\mathrm{Ru}$ particle sizes in $\mathrm{Ru} / \mathrm{TiO}_{2}$ were determined by TEM, BET surface area by $\mathrm{N}_{2}$ physisorption, and Ru weight percent was confirmed by induced coupled plasma (ICP). Additionally, no measurable ethylene conversion was observed on $\mathrm{TiO}_{2}$ alone. $\mathrm{Next}$, ethylene hydrogenation rate at $5 \%$ conversion on $\mathrm{Ru} / \mathrm{CNT}$ and $\mathrm{Ru} / \mathrm{CNT}-\mathrm{Ox}$ was measured and the average $\mathrm{Ru}$ particle size determined by assuming ethylene hydrogenation TOFs remained unchanged (Table S2).

Table S1. Characterization of $\mathrm{Ru} / \mathrm{TiO}_{2}$ catalyst used to measure ethylene hydrogenation TOF

\begin{tabular}{ccccc}
\hline Catalyst & $\begin{array}{c}\text { ICP } \\
(\mathrm{wt} \%)\end{array}$ & $\begin{array}{c}\text { BET Surface Area } \\
\left(\mathrm{m}^{2} / \mathrm{g}\right)\end{array}$ & $\begin{array}{c}\text { Average Particle } \\
\text { size }(\mathrm{nm})\end{array}$ & Dispersion \\
\hline $\mathrm{Ru} / \mathrm{TiO}_{2}$ & 4.4 & 55 & 3.17 & 0.45 \\
\hline
\end{tabular}

Table S2. Metal dispersion and particle size estimated from ethylene hydrogenation experiments

\begin{tabular}{ccccc}
\hline Catalyst & $\begin{array}{c}\text { ICP } \\
(\text { wt } \%)\end{array}$ & $\begin{array}{c}\text { Rate } \\
(\mathrm{mol} / \mathrm{mol} \mathrm{Ru} \mathrm{s})\end{array}$ & Dispersion & $\begin{array}{c}\text { Particle Size } \\
(\mathrm{nm})\end{array}$ \\
\hline $\mathrm{Ru} / \mathrm{CNT}$ & 9.03 & 2.48 & 0.50 & 2.84 \\
$\mathrm{Ru} / \mathrm{CNT}-\mathrm{Ox}$ & 8.66 & 2.38 & 0.48 & 2.98 \\
\hline
\end{tabular}

\section{Assessment of external and internal mass transfer limitations}

When reaction rates are controlled by external mass transfer (from the bulk to the external surface) the observed rate (robs) is given by:

$$
r_{o b s}=k_{c}\left(C_{A}-C_{A S}\right) \approx k_{C} C_{A}
$$

Where $\mathrm{k}_{\mathrm{c}}$ is the mass transfer coefficient, $\mathrm{C}_{\mathrm{A}}$ is the bulk concentration, and $\mathrm{C}_{\mathrm{AS}}$ the surface concentration. $\mathrm{C}_{\mathrm{AS}}$ would be very small due to fast surface reaction; thus, the reaction rate is proportional the value of $\mathrm{k}_{\mathrm{c}}$.

The mass transfer coefficient $\mathrm{k}_{\mathrm{c}}$ is directly proportional to the Sherwood number (Sh) according to the expression

$$
k_{c}=\frac{D_{A B} S h}{d_{p}}
$$

In turn, Sh can be calculated using the Frossling correlation

$$
S h=2+0.6 R e^{1 / 2} S c^{1 / 3}
$$

Therefore, from Eqs. [2] and [3]: 


$$
k_{c}=\frac{D_{A B}}{d_{p}}\left(2+0.6 R e^{1 / 2} S c^{1 / 3}\right)
$$

During external mass transfer tests stirring speeds were varied from 200 to 400 (Figure S1) rpm using a pitched 4-blade turbine type impeller, while keeping all reaction conditions and catalyst properties constant. Therefore, diffusivity (DAB), catalyst particle size (dp), and Schmidt number ( $\mathrm{Sc}$ ) would also remain constant when varying stirring speed. On the other hand, Reynolds number $(\mathrm{Re})$ is proportional to the liquid bulk velocity (U) which is proportional to the stirring speed $(\mathrm{N}) 1$.

$$
R e=\frac{U d_{p}}{v}
$$

Thus,

$$
k_{c}=\frac{D_{A B}}{d_{p}}\left(2+0.6\left(\frac{U d_{p}}{v}\right)^{\frac{1}{2}} S c^{\frac{1}{3}}\right)
$$

And,

$$
k_{c} \alpha U^{1 / 2} \alpha N^{1 / 2}
$$

Therefore, if the system were controlled by external mass transfer limitations changing stirring speed from $200 \mathrm{rpm}$ (1) to $400 \mathrm{rpm}$ (2) should increase the observed rates proportionally even in this range of stirring rates:

$$
\frac{r_{o b s 2}}{r_{o b s 1}}=\frac{k_{c 2}}{k_{c 1}} \approx \frac{N_{2}^{\frac{1}{2}}}{N_{1}^{\frac{1}{2}}}=\left(\frac{400}{200}\right)^{\frac{1}{2}}=2^{1 / 2}
$$

Since the observed reaction rates remained constant as the stirring rate doubled (Figure S1), it can be concluded that external mass transfer does not control the observed rates under the reaction conditions and range of stirring speeds of the study.

1Catalyst particle size (dp) and kinematic viscosity (v) will also remain constant at constant reaction conditions. 


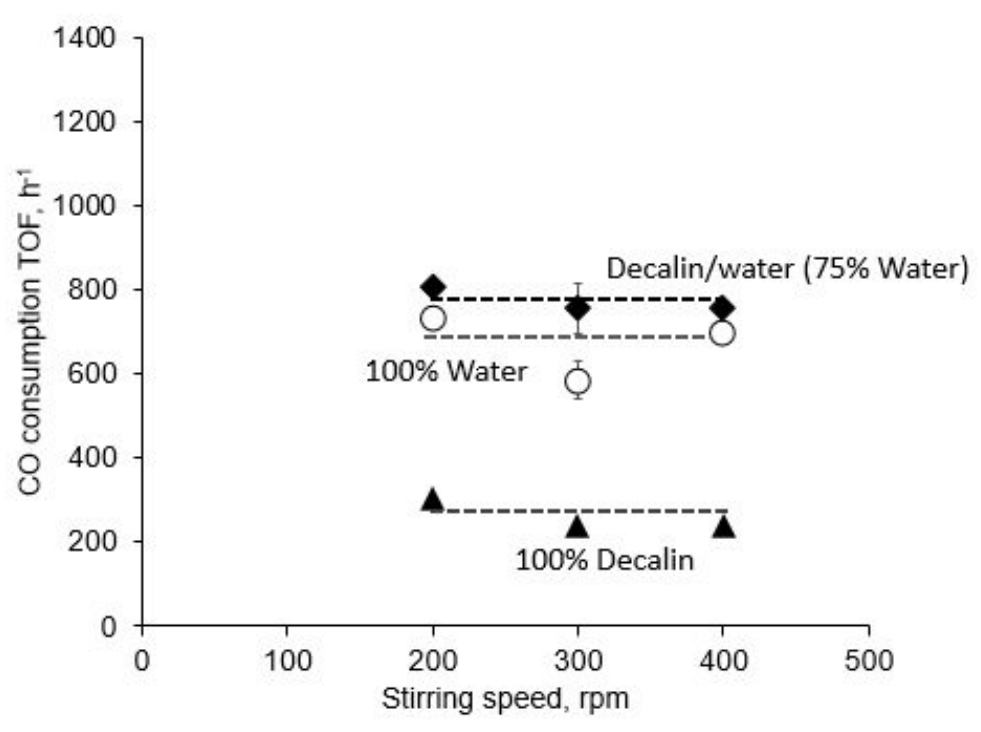

Figure S1. CO consumption rate as function of stirring speed on $\mathrm{Ru} / \mathrm{CNT}$ in single decalin media, single aqueous media, and biphasic oil (decalin)/aqueous media. Reaction conditions: $220 \mathrm{C}, 800 \mathrm{psi}$ $\mathrm{H}_{2} / \mathrm{CO}(4 / 1)$. Conversion $\sim 20 \%$

\section{Ru metal particle size before and after reaction}

Ru metal particle size was measured from TEM images before and after reaction to ensure that metal sintering is not playing a role in the enhanced activity observed in FT in decalin/water emulsions. Figure S2 shows that average metal particle size and size distributions do not change significantly after reaction.

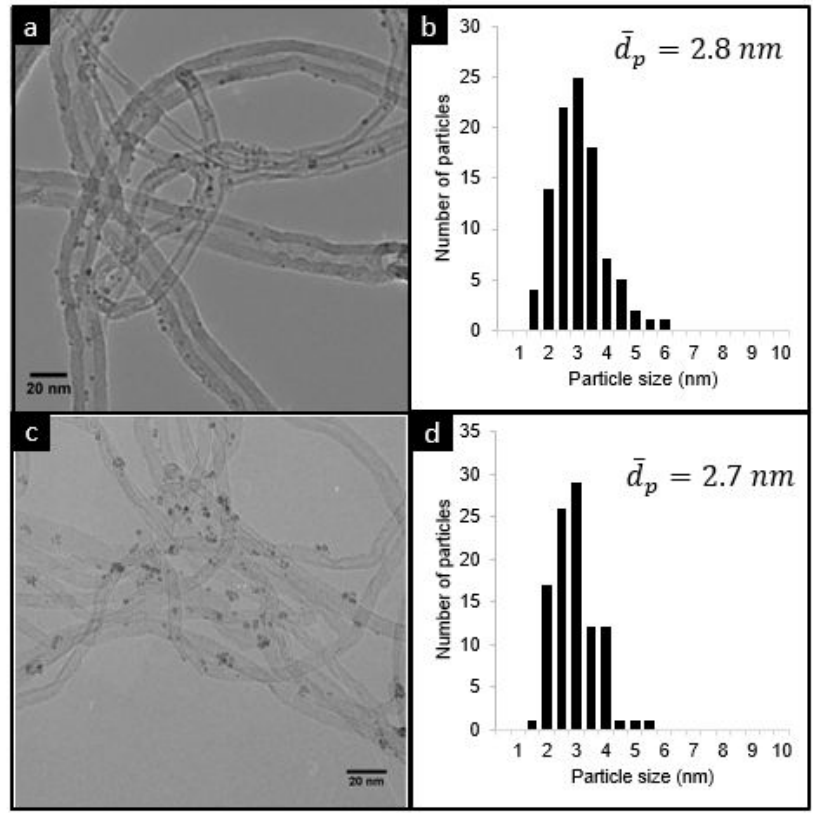

Figure S2 TEM images of $\mathrm{Ru} / \mathrm{CNT}$ before reaction (a) and $\mathrm{Ru} / \mathrm{CNT}$ after reaction in emulsion (b) and their respective particle size distribution histograms, $\mathrm{Ru} / \mathrm{CNT}$ (c) and $\mathrm{Ru} / \mathrm{CNT}$ after reaction (d). Reaction conditions: $87 \%$ Decalin, $13 \%$ Water, Ru/CNT 50mg, $220^{\circ} \mathrm{C}, 800 \mathrm{psi}_{2} / \mathrm{CO}(4 / 1)$, conversion $\approx 18 \%$. 


\section{Characterization of Pickering emulsions}

Following previous studies of the group within our Center of Interfacial Reaction Engineering (CIRE), we have characterized the Pickering emulsions employed in this study with a series of techniques, including optical microscopy, SEM, and TEM of thin slices of solidified wax from one of these emulsions. As described in several studies published by researchers of the center [715], the emulsions are stabilized by the presence of the CNT. Depending on the
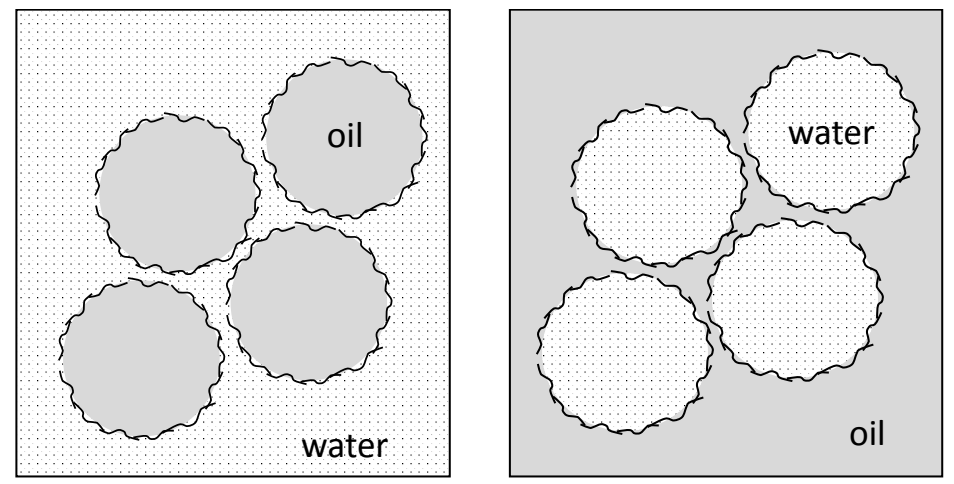

hydrophilicity / hydrophobicity of the CNT, as well as the oil/water ratio in the system, the resulting emulsions are either oil-in-water or water-in-oil (see scheme above). Moreover, as shown in Fig. S3, the droplet size can be tailored by changing the oil/water ratio.

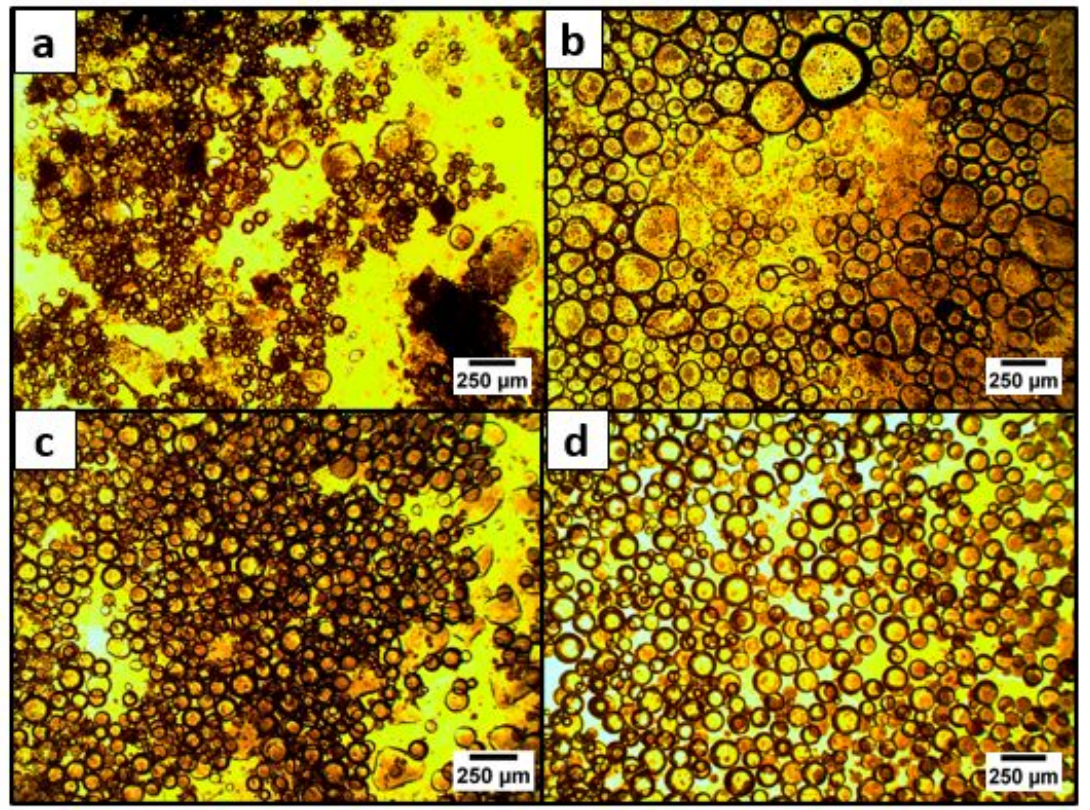

Figure S3 Light microscopy images for water/decalin Pickering emulsion stabilized by Ru/CNT. a) $25 \%$ decalin, b) $50 \%$ decalin, c) $75 \%$ decalin, d) $87 \%$ decalin. Images taken after $24 \mathrm{~h}$ from emulsion preparation.

Finally, as illustrated in Figure S4, it is clearly demonstrated that the emulsion droplets are stabilized by the spreading of CNT along the water/oil interface (e). 


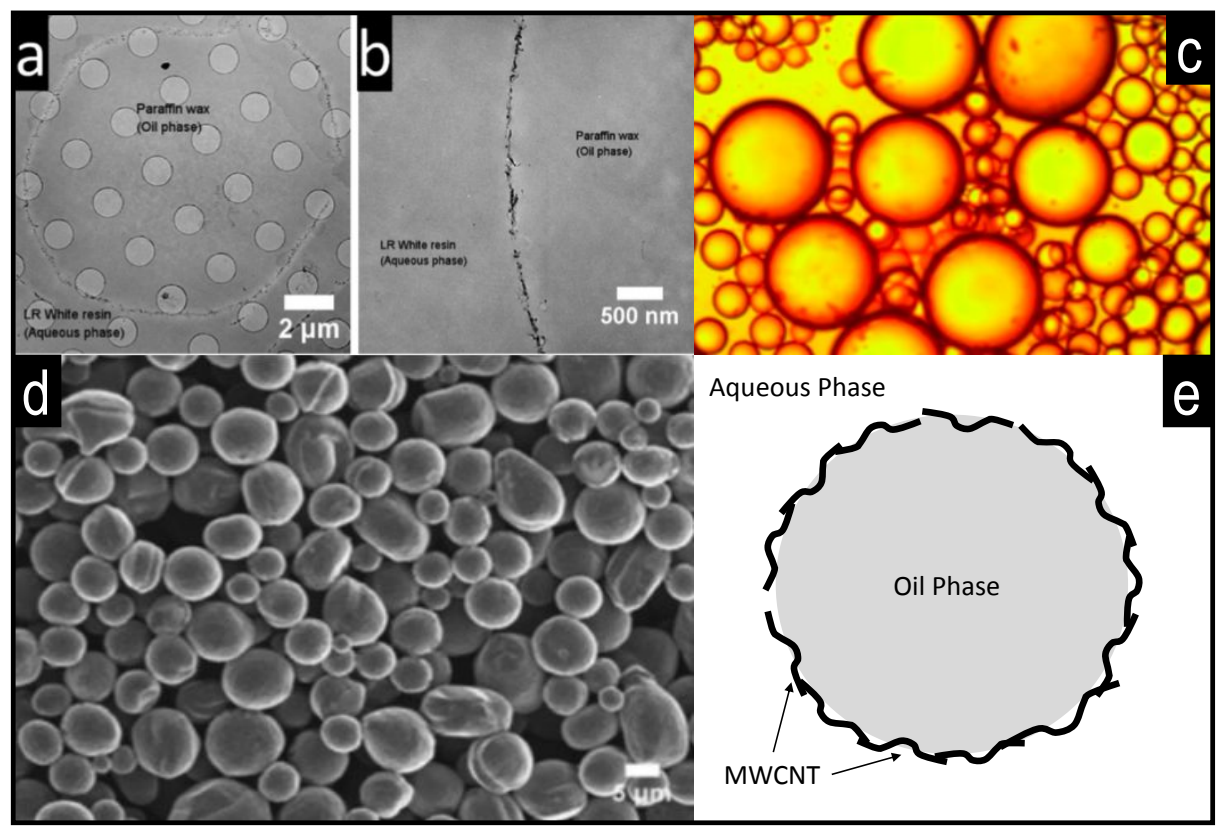

Figure S4. (a,b) TEM images of thin sectioned solidified wax droplets clearly showing the presence of MWNTs at the interface. CNT-Ox at the interface. From Refs. 14, 15; (c) Optical microscope for dodecane and water emulsion stabilized by CNT-Ox. From Refs. 14, 15; (d) SEM images of wax particles formed on cooling of Pickering emulsions using oxidized MWNT (CNT-Ox). From Refs. 14, 15; (e)

Schematic of an oil droplet in an oil-in water emulsion stabilized by CNT-Ox

While optical microscopy clearly shows the characteristics of the oil/water emulsions stabilized by CNT-Ox (Fig. S4 c), a special method had to be developed to investigate the emulsions with electron microscopy. Specifically, we generated paraffin wax/water emulsions at temperatures high enough (60-80 C) to allow the wax to melt and being able to form the emulsion. Upon cooling, the wax solidified (see SEM of solidified wax droplets Fig. S4 d) and allowed us to handle it as a solid sample. Therefore, to obtain TEM images of the CNT at the water/wax interface, the solid droplets were deposited inside a matrix and sliced with a microtome to obtain thin enough samples to be imaged in TEM (see Fig. S4 a and b).

\section{Further discussion on the effect of organic solvents on FT activity}

Fischer-Tropsch synthesis is known to follow a mechanism that kinetically resembles chaingrowth polymerization. In this mechanism, hydrocarbon chain formation goes through initiation, propagation, and termination steps. Additionally, methanation typically occurs as a side reaction. 


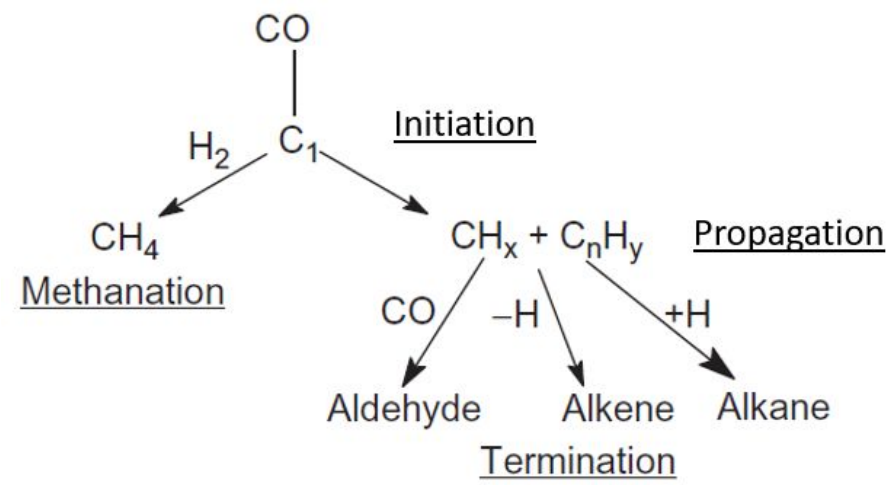

Scheme S1. Fischer-Tropsch Synthesis reaction pathway

In fact, this is the basis for the well-known Anderson-Schulz-Flory distribution (ASF) typical of Fischer-Tropsch products. All experiments in this study followed typical ASF distributions. For example, the graph below shows product distribution for FT on Ru/CNT (Figure 7, 22.5\% water). Higher methanation yields than predicted by ASF distributions are consistent with excess methane produced by a side methanation reactions.

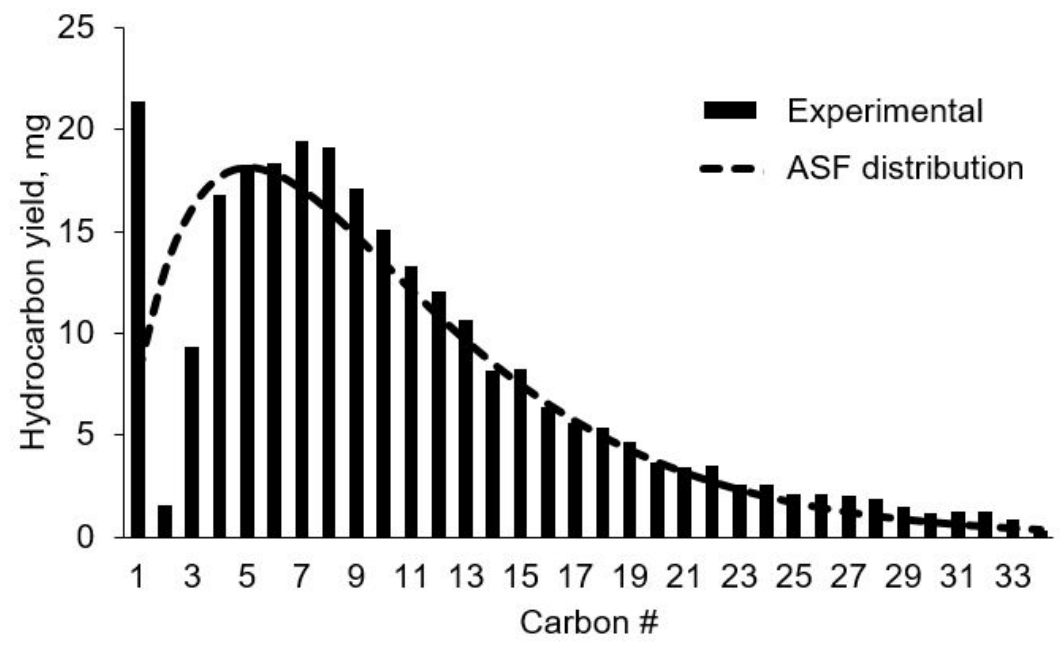

Figure S5. Fischer-Tropsch hydrocarbon distribution on $\mathrm{Ru} / \mathrm{CNT}$ in decalin/water (22.5\% water, $77.5 \%$ decalin). Reaction conditions: $220 \mathrm{C}$, $800 \mathrm{psi}_{2} / \mathrm{CO}(4 / 1), 300 \mathrm{rpm}$, conversion $20 \%$.

After chain initiation, the growing hydrocarbon chain can either 1) add another monomer at a rate proportional to $\mathrm{kp}$ (propagation) or 2 ) terminate a chain at a rate proportional to $\mathrm{kt}$ (termination) 


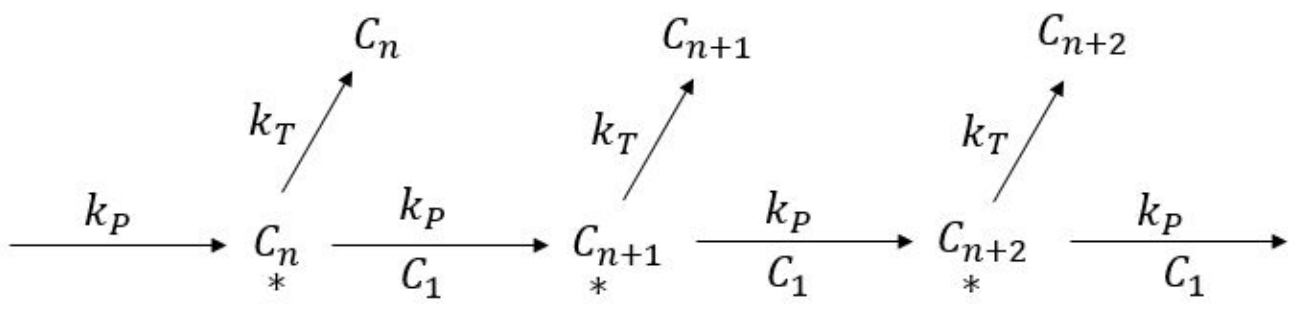

Scheme S2. Fischer-Tropsch hydrocarbon chain-growth

And the chain-growth probability $(\alpha)$ can be calculated as

$$
\alpha=\frac{\text { Rate of propagation }}{\text { rate of propagation }+ \text { rate termination }}
$$

In our experiments, changing the solvent from pure decalin to pure water increased the chaingrowth probability $(\alpha)$ from 0.72 to 0.82 and increased the overall rate of reaction by a factor of 3 (Figure 7). This suggests, in agreement with the literature, that water increases the rate of the rate-limiting initiation step ( $\mathrm{H}$-assisted $\mathrm{CO}$ dissociation) and also the rate of propagation without concomitant increase in the rate of termination.

When the organic solvent is mixed with water in biphasic media the rate of reaction increased by a factor of 2 (Figure 7, 22.5\% water) without change in the chain-growth probability regardless of the ratio of water/organic. As shown below, the chain-growth probability is $0.82+/-0.01$ at water volumes higher than $1.5 \%$.

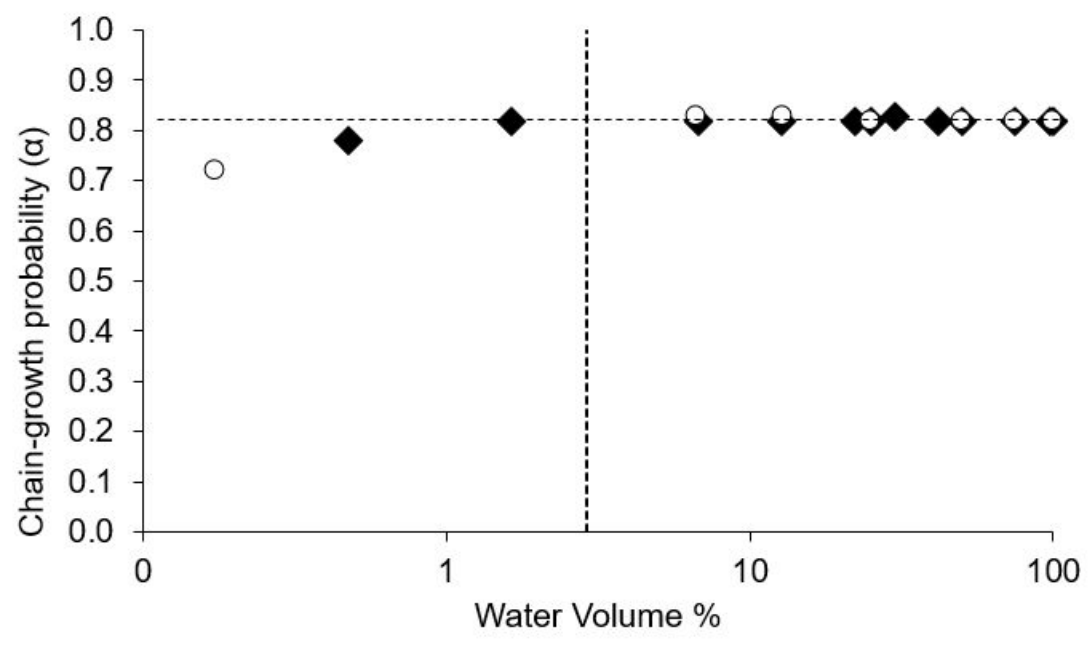

Figure S6. Chain-growth probability $(\alpha)$ on $\mathrm{Ru} / \mathrm{CNT}(\bullet)$ and $\mathrm{Ru} / \mathrm{CNT}-\mathrm{Ox}$ (O) as a function of $\mathrm{H}_{2} \mathrm{O}$ volume fraction $\left(220 \mathrm{C}, 800 \mathrm{psi} \mathrm{H}_{2} / \mathrm{CO}(4 / 1)\right.$, $300 \mathrm{rpm}$, conversion $20 \%$ ) 
Selectivities reported in Figure 8a and b include $\mathrm{CH}_{4}$ produced from methanation which could make it seem that selectivities are changing more than they actually are. Below, the selectivity reported in Figure 8a is corrected by excluding methane produced from side methane-producing reactions. After the correction, it is clear that selectivity to hydrocarbons remains largely unchanged regardless of the ratio of water/organic phase.

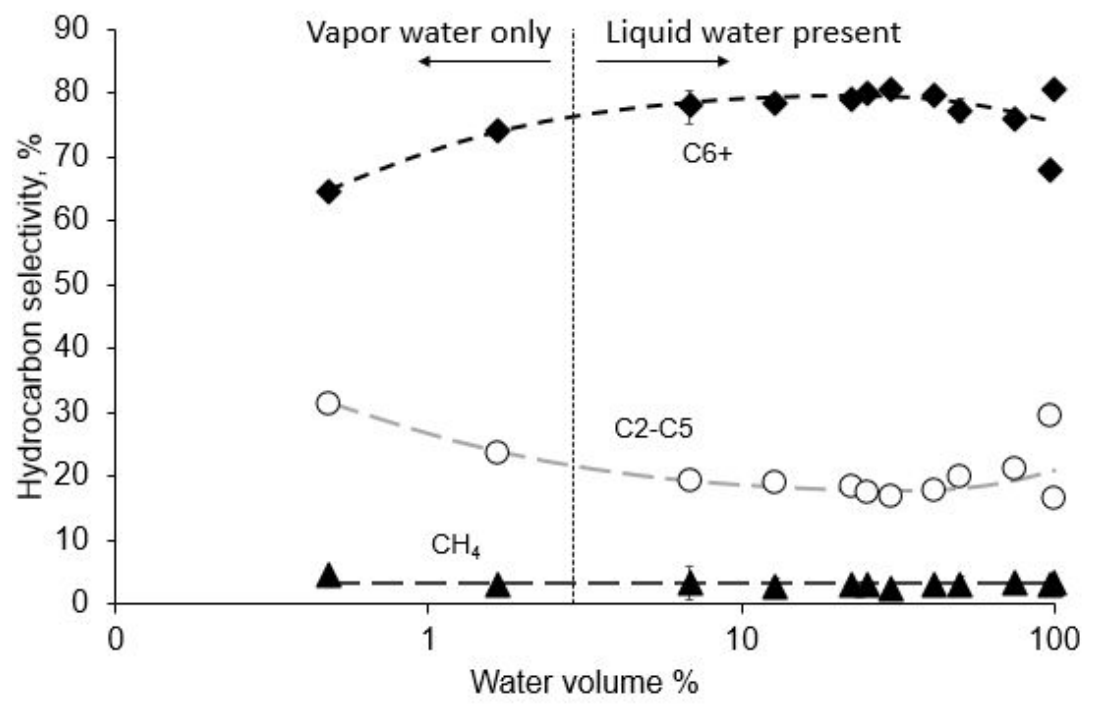

Figure S7. Selectivity to hydrocarbons as a function of water volume fraction excluding $\mathrm{CH}_{4}$ from side reactions: $\mathrm{C} 6+(\bullet), \mathrm{C} 2-\mathrm{C} 5(0), \mathrm{CH}_{4}$ (ム). Reaction conditions: $\mathrm{Ru} / \mathrm{CNT}, 220 \mathrm{C}, 800 \mathrm{psi} \mathrm{H}_{2} / \mathrm{CO}(4 / 1), 300 \mathrm{rpm}$, conversion $\sim 20 \%$.

Therefore, the role of organic solvents is proposed to further enhance the rate of the ratelimiting initiation step (H-assisted CO dissociation) without significantly modifying the rate of propagation or termination. As explained in section 3.7 of the manuscript, recent work by Iglesia et al. has proposed that destabilization of dense $\mathrm{CO}$ adlayers, typical of practical FT, decreases the overall barrier for $\mathrm{CO}$ dissociation by removing the need to desorb and adjacent $\mathrm{CO}$ molecule and create a vacant site required to anchor the "O" atom. We believe it is reasonable to propose that adsorbed decalin or heptane molecules destabilize the dense $\mathrm{CO}$ adlayers in a similar way and reduce the overall energy barrier for the dissociation of CO. Furthermore, Iglesia et al. have proposed that growing hydrocarbon chains effectively disrupt $\mathrm{CO}$ adlayers increasing the rate of $\mathrm{CO}$ dissociation near growing chains, which provides $\mathrm{CO}-$ derived monomers at rates consistent with the formation of long-chain hydrocarbons. Thus, organic solvents do not further increase the rate of propagation by disruption of $\mathrm{CO}$ adlayers because the $\mathrm{CO}$ adlayers near hydrocarbon chains are already effectively disrupted by the same growing hydrocarbon chains. Therefore, organic solvents do not have any effect on the rate of propagation. 
In Fischer-Tropsch synthesis, initiation steps occur every time a hydrocarbon chain forms; followed by propagation, and termination. Since, the organic solvent molecules decrease the energy barrier for the initiation step (CO-dissociation) by destabilizing $\mathrm{CO}$ adlayers, then we

propose that this effect is present every time a hydrocarbon molecule is initiated and should not be restricted to the induction period.

\section{References for Supporting Information}

[1] J.N. Kuhn, C.-K. Tsung, W. Huang, G.A. Somorjai, Effect of organic capping layers over monodisperse platinum nanoparticles upon activity for ethylene hydrogenation and carbon monoxide oxidation, Journal of Catalysis. 265 (2009) 209-215. doi:10.1016/j.jcat.2009.05.001.

[2] D.E. Resasco, G.L. Haller, A model of metal-oxide support interaction for $\mathrm{Rh}$ on $\mathrm{TiO}_{2}$, Journal of Catalysis. 82 (1983) 279-288. doi:10.1016/0021-9517(83)90194-X.

[3] D.S. Jordan, A.T. Bell, Influence of ethylene on the hydrogenation of carbon monoxide over ruthenium, The Journal of Physical Chemistry. 90 (1986) 4797-4805. doi:10.1021/j100411a018.

[4] W.-Z. Li, J.-X. Liu, J. Gu, W. Zhou, S. Yao, R. Si, Y. Guo, H.-Y. Su, C.-H. Yan, W.-X. Li, Y.-W. Zhang, D. Ma, Chemical Insights into the Design and Development of Face-centered cubic Ruthenium Catalysts for Fischer-Tropsch Synthesis, Journal of the American Chemical Society (2017). doi:10.1021/jacs.6b10375.

[5] D.D. Hibbitts, B.T. Loveless, M. Neurock, E. Iglesia, Mechanistic Role of Water on the Rate and Selectivity of Fischer-Tropsch Synthesis on Ruthenium Catalysts, Angewandte Chemie International Edition. 52 (2013) 12273-12278. doi:10.1002/anie.201304610.

[6] J.M.G. Carballo, J. Yang, A. Holmen, S. García-Rodríguez, S. Rojas, M. Ojeda, J.L.G. Fierro, Catalytic effects of ruthenium particle size on the Fischer-Tropsch Synthesis, Journal of Catalysis. 284 (2011) 102-108. doi:10.1016/j.jcat.2011.09.008.

[7] D. Shi, J.A. Faria, A.A. Rownaghi, R.L. Huhnke, D.E. Resasco, Fischer-Tropsch Synthesis Catalyzed by Solid Nanoparticles at the Water/Oil Interface in an Emulsion System, Energy \& Fuels. 27 (2013) 6118-6124. doi:10.1021/ef401198m.

[8] N Pino, T Bui, G Hincapié, D López, DE Resasco, Hydrophobic zeolites for the upgrading of biomass-derived short oxygenated compounds in water/oil emulsions, Applied Catalysis A: General 559, 94-101 (2018)

[9] Paula A. Zapata, Jimmy Faria, M. Pilar Ruiz, Daniel E. Resasco, Condensation/hydrogenation of biomass-derived oxygenates in water/oil emulsions stabilized by nanohybrid catalysts, Topics in Catal., 55, 38-53 (2012) 
[10] Ruiz M. Pilar; Faria Jimmy; Shen Min; Drexler, Santiago; Prasomsri, Teerawit; Resasco, Daniel E., Nanostructured Carbon-Metal Oxide Hybrids as Amphiphilic Emulsion Catalysts, ChemSusChem 4, 964-974 (2011)

[11] Jimmy Faria, M. Pilar Ruiz, Daniel E. Resasco, Phase-Selective Catalysis in Emulsions Stabilized by Janus Silica-Nanoparticles, Advanced Synthesis \& Catalysis, 352, 2359-2364 (2010)

[12] Steven Crossley, Jimmy Faria, Min Shen, Daniel E. Resasco, Solid Nanoparticles that Catalyze Biofuel Upgrade Reactions at the Water-/Oil Interface, Science, 327, 68 (2010)

[13] Min Shen and Daniel E. Resasco, Emulsions Stabilized by Carbon Nanotube-Silica Nanohybrids, Langmuir 25, 10843-10851 (2009)

[14] Nicholas Briggs, Carbon Nanotubes as Catalyst Supports in Biphasic Systems, PhD Dissertation, University of Oklahoma (2016)

[15] Briggs, Nicholas M ; Weston, Javen S ; Li, Brian ; Venkataramani, Deepika ; Aichele, Clint P ; Harwell, Jeffrey H ; Crossley, Steven P., Multiwalled Carbon Nanotubes at the Interface of Pickering Emulsions, Langmuir, 31, 13077-84 (2015) 